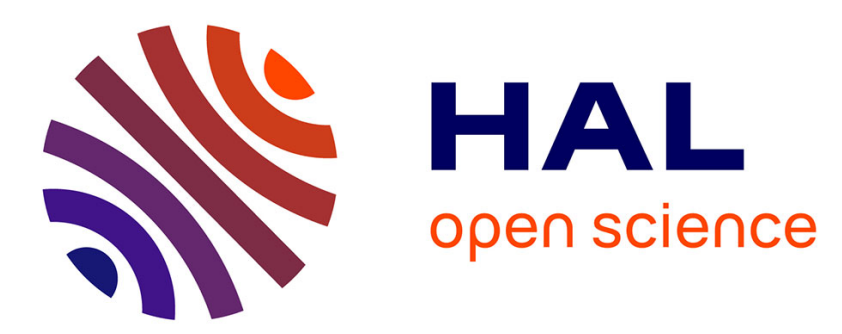

\title{
Impact of Changes in Quality of Deliveries on the Vulnerability of Supply Chains
}

Leila Sakli, Jean-Claude Hennet, Jean-Marc Mercantini

\section{To cite this version:}

Leila Sakli, Jean-Claude Hennet, Jean-Marc Mercantini. Impact of Changes in Quality of Deliveries on the Vulnerability of Supply Chains. 16th Working Conference on Virtual Enterprises (PROVE), Oct 2015, Albi, France. pp.578-587, 10.1007/978-3-319-24141-8_54 . hal-01437924

\section{HAL Id: hal-01437924 \\ https://inria.hal.science/hal-01437924}

Submitted on 17 Jan 2017

HAL is a multi-disciplinary open access archive for the deposit and dissemination of scientific research documents, whether they are published or not. The documents may come from teaching and research institutions in France or abroad, or from public or private research centers.
L'archive ouverte pluridisciplinaire HAL, est destinée au dépôt et à la diffusion de documents scientifiques de niveau recherche, publiés ou non, émanant des établissements d'enseignement et de recherche français ou étrangers, des laboratoires publics ou privés.

\section{(c)(1)}

Distributed under a Creative Commons Attribution| 4.0 International License 


\title{
Impact of Changes in Quality of Deliveries on the Vulnerability of Supply Chains
}

\author{
Leila Sakli, Jean-Claude Hennet, Jean-Marc Mercantini \\ Aix Marseille University, CNRS, ENSAM, Toulon University, LSIS UMR \\ 7296,13397, Marseille, France \\ \{leila.sakli, jean-claude.hennet, jean-marc.mercantini\}@1sis.org
}

\begin{abstract}
The main objectives of the study are to present the vulnerability of the supply chain related to the change in the quality of the products supplied, and propose solutions to mitigate its disturbance. We use ARMA (Auto Regressive Moving Average) time series to model a supply chain with one supplier and one retailer. We then analyze how changes in the quality of products delivered by the supplier may affect the system variables, taking into account the system constraints and the uncertain demand from customers. A quality predictor can then be introduced in the model to improve the resilience of the chain.
\end{abstract}

Keywords: Risk, supply chain, vulnerability, resilience, quality.

\section{Introduction}

New technologies and globalization increase the complexity of supply chains and therefore expose them to risks of different types. Faced with uncertainty, supply chains appear more sensitive in the context of competitive pressure, unpredictable and volatile global market demand. In particular, supply chains are sensitive to local disturbances and uncertainties related to demand [1] supplies [2] or information [3], [4]. Several studies have been conducted to analyze the topic of risk especially in the context of the supply chain [5] [6]. In general, risk is a combination of a probability of occurrence of an adverse event and a measure of the severity of the consequences of this event in terms of damage or injury (ISO / CEI73) [7]. The concept of risk is significant only in the presence of targets vulnerable to the effects of hazards induced by accidents [8].

Vulnerability is an intrinsic property of a system. It measures its sensitivity to adverse events. We distinguish endogenous vulnerabilities, which are properties of the companies that make up the supply chain, and vulnerabilities external to the company, at the level of interconnections between companies or flows [9].

In the field of the supply chain, Ou Tang and Nurmaya Musa [10] argue the lack of a difference between uncertainty and risk in the literature. However, as [6] we distinguish between these two concepts. Indeed according to ISO / 2009, the risk is defined as the effect of uncertainty on objectives [11]. This definition highlights both 
the difference and the relationship between the concepts of risk and of uncertainty. Under the effect of uncertainty, a deviation can be positive or negative. In practice, one is interested in the negative effect [6]. In this context Wagner and Bode [9] define risk as "the negative deviation from the expected value of a certain performance measure, resulting in negative consequences for the focal firm" [9].

Due to the complex structures of today supply chains, a risk in a company may have consequences for other companies upstream or downstream. It thus threatens the entire chain. The resilient supply chain has the ability to adapt whatever the events to which the chain is subjected. Resilience is "the system's ability to return to a new stable situation after an accidental event" [13]. Taking into account that it is a multidimensional concept, Serhiy Y et al.[14] define resilience as "the adaptive capability of the supply chain to prepare for unexpected events, respond to disruptions, and recover from them by maintaining continuity of operations at the desired level of connectedness and control over structure and function" [14]. To preserve the resilience of supply chains, the areas of risk analysis and risk management are currently acquiring great interest, both from the theoretical and applicative standpoints. It is necessary to have indicators of vulnerabilities in the chain to determine the sensitivity of the chain to adverse events and to characterize the system's lack of resilience.

To form a resilient supply chain, the company must select the most reliable suppliers. Product quality is among the key factors in determining the reliability of a supplier, and the quality of a product may critically depend on risks in production, delivery or storage. In this research, we focus on uncertainties about the quality of supplied components and the demand, and try to analyze the vulnerability of the supply chain due to the variation in the quality of the product supplied. In a previous work [5], we have proposed a model based on ARMA time series to study supply chain vulnerabilities under demand uncertainty. The choice of ARMA time series can be argued by the fact that such model takes into account both the random nature of the system and its history.

As shown in the next section, starting from the works of Box and Jenkins [16] for ARMA series and Gilbert [16] for their applications to modeling supply chain dynamics, we have introduced in the model constraints on inventory and supplier capacity. From this non-linear model, we can infer indicators of system vulnerability. After that, we add to this model a quality index. First, the product quality model is supposed ARMA and can be estimated based on the history of deliveries from the same supplier. Next, the product quality model is supposed determinist with random time. In section 3, and to simplify the study, we consider a basic two-stage supply chain consisting of a company and its supplier receiving random demands from customers. The dynamics of the system are studied by simulation, to measure the influence of quality uncertainty and compare the cases when quality variations are anticipated and when they are not, and also to compare between the different models of quality index. 


\section{Model Development}

In this section we start by modeling the supply chain with ARMA. In many cases, supply chains "can be viewed as virtual systems subject to dynamic reconfigurations, through arrival or departure of partner enterprises. » [8]. The formulation of the model is as follows. To represent the model of the supply chain, we use the following notation:

$D_{t}:$ Random demand at period $\mathrm{t}$

$a_{t-1}, e_{t}, \varepsilon_{t}:$ White noises

$\mu$ : mean demand

$I_{t}:$ Inventory level at the end of period $\mathrm{t}$

$O_{t}:$ Order placed at the end of period $\mathrm{t}$

$\hat{D}_{t}$ : Estimated value of demand at period $\mathrm{t}$

$\bar{I}$ : Maximal storage capacity

$I I_{t}:$ Inventory index at period $\mathrm{t}$

$\bar{O}$ : Maximal quantity ordered from the supplier in one period

$O I_{t}:$ Order index at period $\mathrm{t}$

$z_{t}$ : Quality index at period $\mathrm{t}$

$\hat{z}_{t}$ : Estimated quality index at period $\mathrm{t}$

$S:$ Safety stock level

\subsection{Model of the Supply Chain}

The modeling of the chain is given by the representation of the demand, the level of stock of each company and the quantity of products or components to be ordered.

When a prime contractor places orders to his supplier, it also transmits information about customer demand. This demand is often of random nature. A mathematical formulation of the demand $D_{t}$ can be constructed by the method of Box and Jenkins [15] as an ARIMA (p, d, q) (Auto Regressive Integrated Moving Average). The main purpose of this model is to predict the future values of the random demand, taking into account its previous values observed.

$$
D_{t}=\mu+\sum_{k}^{p} \varphi_{k}\left(D_{t-k}-\mu\right)+a_{t}+\sum_{l=1}^{q} \theta_{l} a_{t-l}^{\perp} .
$$

Based on this representation, Gilbert [16] proposed a linear model of the supply chain by introducing the stock level $I_{t}$, and the order quantity $O_{t}$ at the end of period $\mathrm{t}$ according to the forecast demand $\hat{D}_{t+k} \cdot \hat{D}_{t+k}$ is calculated by using a forgetting factor $\alpha$. Starting from a series of stationary demand, Gilbert demonstrated that the stock and order are also ARMA [16]. The ARMA model is a special case of 
the ARIMA model mentioned above. It treats the stationary series. If the series is not stationary, its variable is integrated until stationarity, hence the letter I in the model name. In the model below, we assume that the order policy is the classical "Order up to policy".

$$
I_{t}=I_{t-1}+O_{t-L}-D_{t}
$$

and

$$
O_{t}=S-I_{t}+\hat{D}_{t}(1)+\ldots+\hat{D}_{t}(L)-O_{t-1}-\ldots-O_{t-L+1}
$$

By definition, $S$ is the level of safety stock required to limit stock-outs. A study that generalizes this order policy was also proposed by Gilbert et al. [17]. The ARMA model also allows the chain to represent a widely known vulnerability in the field of supply chain, known as the bullwhip effect [5] [16] [1]. It represents the amplification phenomenon of demand variability in the stages upstream in the supply chain. The proposed model allows evaluation of the bullwhip effect on the stock and on the order. Note that another phenomenon is also studied in the literature regarding the reverse bullwhip effect. It aims to evaluate the amplification of disturbances in the prices of raw materials on the downward stages and determine its effect on the product's final cost [18].

\subsection{The Constrained Model}

The model of the supply chain presented above does not take into account the constraints of the companies. In real cases, the company has a limited storage capacity and cannot order more than a maximal amount of products from the supplier. At the other end of the feasibility intervals, the level of the stock and the quantity delivered cannot have negative values. To take these constraints into account, Sakli et al. [5] present a saturated ARMA model, in which the dynamic equations (2), (3) are replaced by the following non-linear equations.

Inventory equations. Due to the limits on the storage capacity, the current inventory level is computed by:

$$
\left\{\begin{array}{l}
I_{t}=\min \left(I_{t-1}+O_{t-L}-D_{t}, \bar{I}\right) \\
I_{t}=\max \left(I_{t-1}+O_{t-L}-D_{t}, 0\right)
\end{array} .\right.
$$

Order equations. Due to the limits on the quantity ordered, the current order is computed by:

$$
\left\{\begin{array}{ll}
O_{t}=\min & \left(S-I_{t}+\hat{D}_{t}(1)+\ldots+\hat{D}_{t}(L)-O_{t-1}-\ldots-O_{t-L+1}, \bar{O}\right) \\
O_{t}=\max & \left(S-I_{t}+\hat{D}_{t}(1)+\ldots+\hat{D}_{t}(L)-O_{t-1}-\ldots-O_{t-L+1}, 0\right)
\end{array} .\right.
$$




\subsection{Representation of the Quality Problem}

When a requested quantity is produced or delivered, this amount may not have the desired quality or be delivered within the scheduled time. The variation of product quality can be caused by the production process, but also by the delivery, because of the handling or transport of the goods or by storage. The amount of products that do not meet the desired quality can either be returned to the supplier, be accepted by the company at a lower price, or considered as waste and therefore discarded. This depends on the nature of the goods and the severity of the defect.

Let $z_{t}$ be an index of the quality of supply in period t. The quality of goods is supposed variable in time. Two cases are analyzed in this study: either $z_{t}$ is random with variations around a mean value or $O_{t}$ takes two values: 0 and 1 with deterministic jumps occurring at random times.

Case of random variations. An example of random variations is when $z_{t}$ is supposed ARIMA $(0,1,1)$. In fact, this model of quality must be truncated as follows, to avoid quality values under 0 or above 1 .

$$
\left\{\begin{array}{l}
e_{\mathrm{t}} \mathrm{N}(0, \operatorname{sigma}) \\
\zeta_{\mathrm{t}}=h+e_{\mathrm{t}} \\
z_{t}=\zeta_{\mathrm{t}} \text { if } 0 \leq \zeta_{\mathrm{t}} \leq 1 . \\
z_{t}=1 \text { if } \zeta_{\mathrm{t}}>1 \\
z_{t}=0 \text { if } 0<\zeta_{\mathrm{t}}
\end{array} .\right.
$$

Case of deterministic values with random jumps. A typical example of this case is given by formula (7).

$$
\left\{\begin{array}{l}
z_{t}=1 \text { if } 0 \leq t<T 1 \quad \text { Or if } T 2 \leq t<T 3 \text { Or if } T 4 \leq t \leq T \\
z_{t}=0 \text { if } T 1 \leq t<T 2 \text { Or if } T 3 \leq t<T 4
\end{array}\right. \text {. }
$$

$T 1, T 2, T 3$ and $T 4$ are random dates that may be obtained in simulation from uniform laws in given intervals.

$z_{t}=1$ is the case when the quantity ordered respects the desired quality. The opposite case, $z_{t}=0$ represents the case when the supplier cannot deliver the requested products with the required quality. Such a case may be due to interruption of production (machines' breakdown, strikes, etc.), or transportation problems.

Whatever the law of evolution of $z$, the dynamic equation of evolution of the stock is constrained by saturation values in the following form:

$$
\left\{\begin{array}{l}
I_{t}=\min \left(I_{t-1}+O_{t-L} * z_{t}-D_{t}, \quad \bar{I}\right) \\
I_{t}=\max \left(I_{t-1}+O_{t-L} * z_{t}-D_{t}, \quad 0\right)
\end{array}\right. \text {. }
$$

It can be noted that the unconstrained model is bilinear. Moreover, integration of constraints as in section 2.2 introduces other nonlinearities. To compensate for the 
lack of reliability of the supplier, it is possible to adjust the value of the quantity to order based on the predicted quality of delivery. For this, we propose to build a quality predictor, taking value $\hat{z}_{t}$ at time $t$. Under this assumption and after introduction of constraints saturation, the equation for the order is:

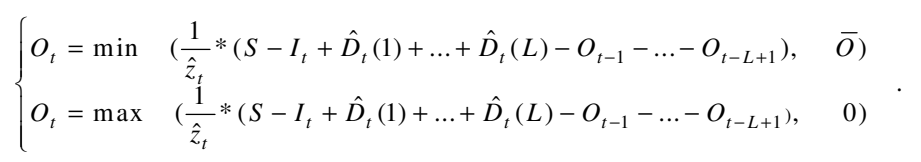

For example, a predictor $\hat{z}_{t}$ can be calculated recursively with a forgetting factor $f$ as follows:

$$
\hat{z}_{t}=(1-f) * \hat{z}_{t-1}+f * z_{t-1}
$$

In the previous expression, $z_{t-1}$ is known, measured at time $\mathrm{t}-1$ by inspection of the delivery of order $O_{t-L+1}$, which has just been received at time t- 1 .

Equations (9) tend to increase the order from the supplier up to its maximal capacity. This increase corresponds to the collaboration mechanism between the supplier and the producer to better satisfy customers.

Detecting the saturation of the system further allows the construction of indices that keep in memory the information on the occurrence of saturation.

Saturation index of the inventory: $\left\{\begin{array}{llc}I I_{t}=-1 & \text { if } & I_{t}=0 \\ I I_{t}=0 & \text { if } & 0<I_{t}<\bar{I} \\ I I_{t}=1 & \text { if } & I_{t}=\bar{I}\end{array}\right.$.

Saturation index of the order: $\left\{\begin{array}{llc}O I_{t}=-1 & \text { if } & O_{t}=0 \\ O I_{t}=0 & \text { if } & 0<O_{t}<\bar{O} \\ O I_{t}=1 & \text { if } & O_{t}=\bar{O}\end{array}\right.$.

\section{A Case Study}

The case study concerns a basic two-stage supply chain with a company (producer) and its supplier. The company receives random orders from customers. The demand is supposed ARMA $(0,1,1)$ with a fixed delivery lead time $L$, and is written as follows. Here $\varepsilon_{t}$ denotes as the white noise, representing an additive system disturbance.

$$
D_{\mathrm{t}}=\bar{D}+\varepsilon_{\mathrm{t}}
$$

A demand predictor is constructed by recursive forecast with forgetting factor $\alpha$ :

$$
\hat{D}_{t}=(1-\alpha)^{*} \hat{D}_{t-1}+\alpha^{*} D_{t-1} .
$$


In numerical examples, the selected value of the forgetting factor is $\alpha=0.15$. The curves of demand $D_{t}$ and predicted demand $\hat{D}_{t}$ are shown in Fig.1.

To validate the analytical results, we represent the influence of changes in quality in the two cases previously presented. For both cases, the system is simulated with and without a quality predictor given by (10) with forgetting factor $f=0.55$, to evaluate the accuracy and effectiveness of this predictor to improve the system resilience.
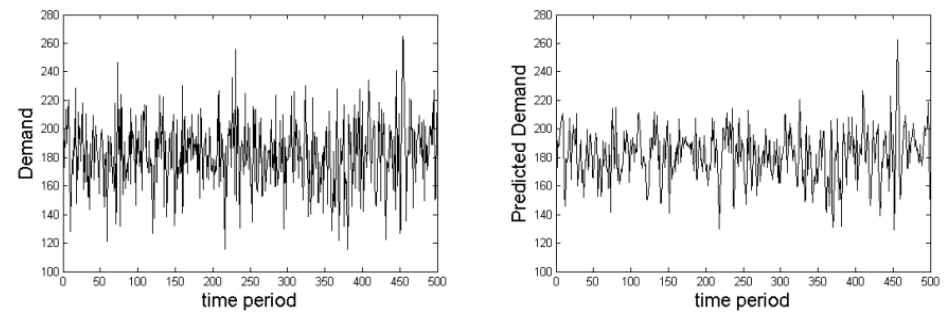

Fig. 1. Curve of demand and predicted demand

\subsection{Simulation under the Multiplicative Quality Disturbance}

Firstly, we simulate the system dynamics with a random quality index $z_{t}$. The mean value of quality is supposed to be 0.8 . Of course, this value is not supposed to be known by the producer, who computes the order value by formula (9).

Simulation without quality disturbance prediction. The quality index $z_{t}$ is simulated by formula (6). Fig. 3 describes the evolutions of the inventory $I_{t}$ computed by (8) and the order $O_{t}$ computed by (9) with $\hat{z}_{t}=1$. In this simulation, the quality defects are unknown and there is no prediction of the quality index $\left(\hat{z}_{t}=1\right)$. This figure provides some insights on the system behavior. In particular, it can be noted that the inventory level is often zero and the inventory index (11) takes value -1 . It represents the case when demand $D_{t}$ is greater than the quantity available in stock $I_{t}$.
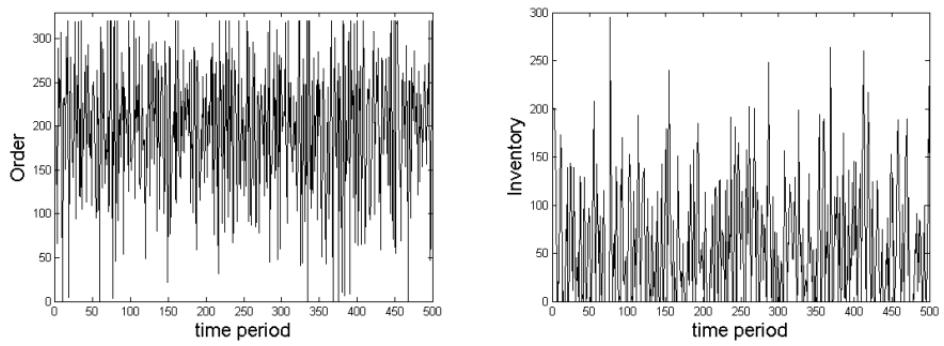

Fig. 2. Order and inventory evolutions with $\widehat{z}_{t}=1$ 
Due to the high frequency of stock-outs, it seems necessary to take into account the quality perturbation in the order process.

Simulation with quality disturbance prediction. Under the quality index predicted by formula (10), the system has a less vulnerable behavior. It can be observed on Fig. 3 that the mean value of inventory seems stationary. However, the order values computed by (9) are frequently hitting the maximal delivery level.
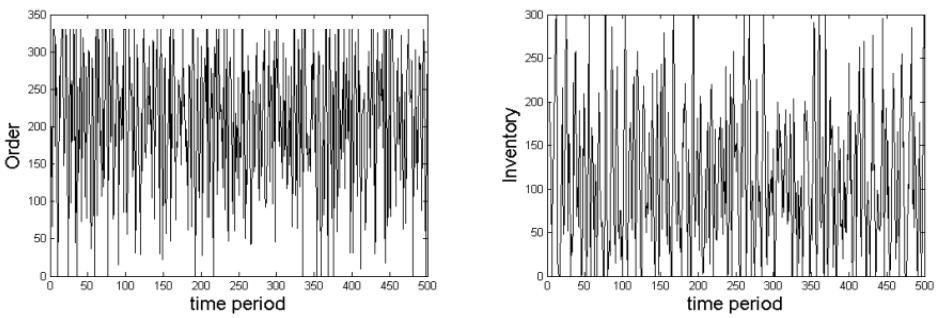

Fig. 3. Order and inventory evolutions

\subsection{Simulation with Quality Jumps at Random Times}

The system is now simulated under random jumps of the quality percentage between 0 and 1 at random times. Again, the system is first simulated without any quality disturbance predictor $\left(\hat{z}_{t}=1\right)$ and with the same predictor as in the previous example ( $\hat{z}_{t}$ given by (10)).

In this numerical example, the dates $\mathrm{T} 1=177, \mathrm{~T} 2=227, \mathrm{~T} 3=395$ and $\mathrm{T} 4=431$ have been chosen at random by uniform laws in given intervals of dates. As shown in Fig. 4, the quality index is 1 between the dates (0: 177), (228: 395) and (432: 500). In these intervals, quality is perfect and there is no defective products discarded. On the contrary, the quality index is zero between dates (178: 227) and (396: 431).

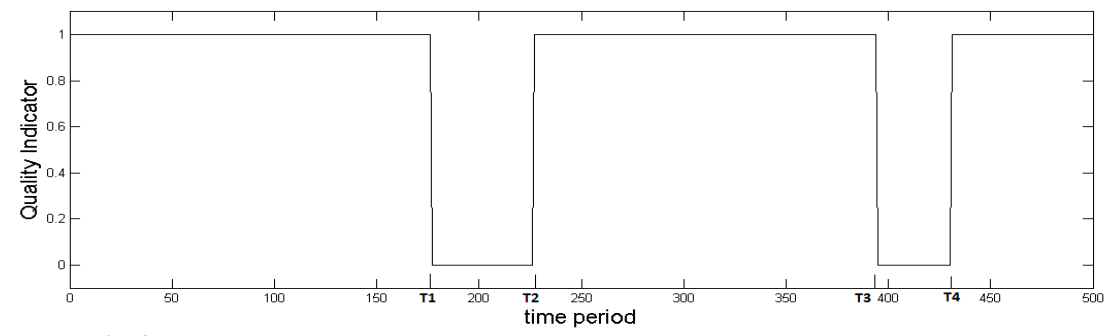

Fig.4. A curve of quality index evolution with randomly generated commutations

Simulation without quality disturbance prediction. We have first simulated the system with $\hat{z}_{t}=1 \forall t \in\left[\begin{array}{ll}0 & 500\end{array}\right]$. Fig.5 illustrates the order and inventory evolutions without any prediction of the quality index. 

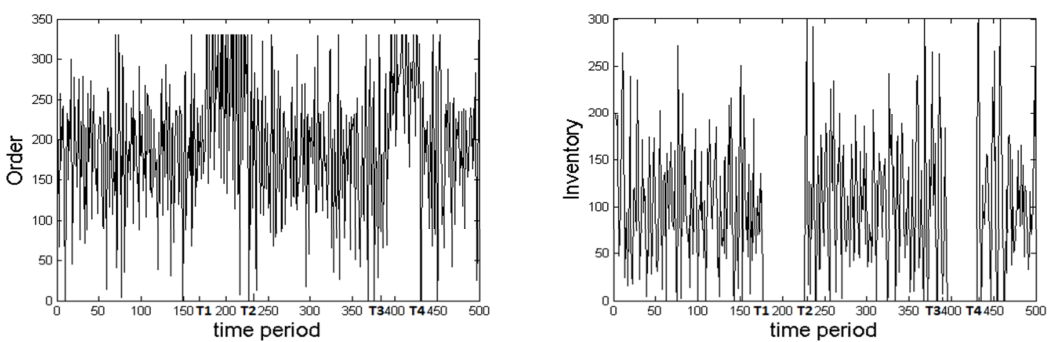

Fig. 5. Order and inventory evolutions

Simulation with quality disturbance prediction. To predict the quality index, we use formula (10) again, with forgetting factor $f=0.55$. The curve of the estimated index is very close to the quality index of Fig. 4. However, it can be observed on Fig. 6 that the order and inventory evolutions are still strongly disturbed around the dates of the states changes.
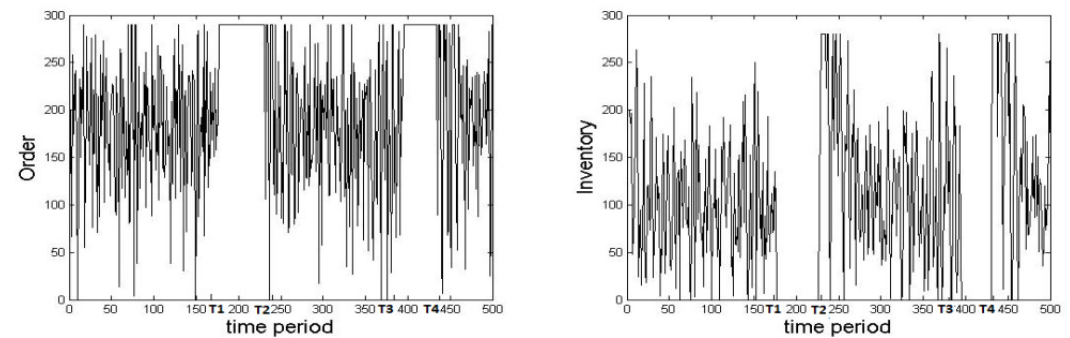

Fig. 6. Order and inventory evolutions

It is clear that the system gets out of stock throughout the supplier interruption period. On the other hand, the order level commonly reaches the maximum threshold value 330 of the supplier's capacity. However, such a systematic increase of the order level during supplier breakdown periods has limited effect on the inventory curve since deliveries are zero regardless of the amount of the order.

\section{Conclusion}

This paper presented concepts related to risks in a supply chain, namely uncertainty, vulnerability and resilience. We proposed a nonlinear model based on time series ARMA for representing a supply chain, taking into account the constraints of the real system. Then, we simulated the system subject to random disturbances on demand and supply, under positivity and capacity constraints on the quantity ordered and available stock. Two types of quality disturbances from the supplier were simulated. In both cases, it is clear that without taking into account the quality index, the system often is often out of stock and gets into strong disturbance that propagate upward and downward the supply chain. To mitigate that problem, we have proposed to construct 
a quality predictor, and we have introduced it into the formula for calculating the order quantity. If out of stock, the company orders a larger quantity often equal to the maximum capacity of the supplier. This corrective policy appears to be efficient in the case of random fluctuations of the quality. But its impact is rather limited in the allor-nothing supply quality case.

\section{References}

1. Lee, H.L., Padmanabhan, V. et Seungjin, W.: Information distorsion in a supply chain: The bullwhip effect. Management Science, vol. 43, n 4, pp. 546 - 558 (1997)

2. So K.C., Zheng X... Impact of supplier's lead time and forecast demand updating on retailer's order quantity variability in a two-level supply chain. Int. J. Production Economics, vol 86, pp169-179 (2003)

3. Huang G.Q., Lau J.S.K., Mak K.L.: The impacts of sharing production information on supply chain dynamics : a review of the literature. International Journal of Production Research, vol 41, pp 1483--1517 (2003)

4. Babai M.Z., Ali M.M., Boylan J.E., Syntetos A.A.: Forecasting and inventory performance in a two-stage supply chain with $\operatorname{ARIMA}(0,1,1)$ demand: Theory and empirical analysis. Int. J. Production Economics, vol 143 (2), pp. 463-471 (2013)

5. Sakli L., Hennet J-C., Mercantini J-M.: An Analysis of Risks and Vulnerabilities in Supply Networks, in : Elsevier, Preprints of the19th World IFAC Congress, Cape Town South Africa, IFAC, pp. 8933-8938 (2014)

6. Manuj I.; Mentzer J.T..: Global supply chain risk management. Journal of Business Logistics, vol 29, pp 133--155 (2008)

7. ISO-IEC guide 73. http://www.iso.org.

8. Hennet, J.C., Mercantini, J.M., Demongodin, I.: Toward an integration of risk analysis in supply chain assessment. Proc. I3M-EMSS, pp. 255-260 (2008)

9. Wagner S.M., Bode C.: An Empirical Investigation into Supply Chain Vulnerability. J. Purchasing \& Supply Management, vol. 12, pp. 301-312. (2006)

10. Ou Tang, Nurmaya Musa, S.: Identifying risk issues and research advancements in supply chain risk management. Int. J. Production Economics, vol. 33, pp. 25-34 (2010)

11. ISO2009 http://www.iso.org.

12. Wagner S.M., Bode C.: Dominant Risks and Risk management Practicis in Supply Chain. In: George A. Zsidisin,Bob Ritchie,: Supply Chain Risk: A Handbook of Assessment, Management, and Performance pp 271-292, Springer (2008)

13. Asbjørnslet B.E.: Assessing the Vulnerability of Supply chain. In: George A. Zsidisin,Bob Ritchie,: Supply Chain Risk: A Handbook of Assessment, Management, and Performance pp 271-292, Springer (2008)

14. Ponomarov S.Y., Holcomb M.C.: Understanding the concept of supply chain resilience The Int. J. of Logistics Management, vol. 20, pp. 124-143 (2009)

15. Box, G.E.P, Jenkins, G.M.: Time series analysis: forecasting and control. San Francisco: Holden-Day (1976)

16. Gilbert, K.C.: An ARIMA supply chain model. Management Science, vol. 51, pp. 305$310,(2005)$

17. Gilbert, K.C., Chatpattananan V., : An ARIMA supply chain model with a generalized ordering policy, Journal of Modelling in Management, vol. 1, pp.33 - 51 (2006)

18. Rong, Y., Snyder, L. V., Zuo-Jun M.S.: Bullwhip and Reverse Bullwhip Effects under the Rationing Game (2008). http://dx.doi.org/10.2139/ssrn.1240173 